\title{
A ALFABETIZAÇÃO NOS MANUAIS DIDÁTICOS: O ESTADO DA ARTE
}

\author{
Enilda Fernandes \\ Universidade Estadual de Mato Grosso do Sul \\ enilda@uems.br \\ Iara Augusta da Silva \\ Secretaria de Estado de Educação de Mato Grosso do Sul \\ Iasilva1@terra.com.br
}

\section{RESUMO:}

O presente trabalho compõe pesquisa em andamento, "A Alfabetização nos Manuais Didáticos Utilizados na Escola Normal de São Paulo para a Instrução dos Normalistas (1909-1945)". A temática e o método vinculam-se a uma pesquisa interinstitucional, "O Manual Didático como instrumento de trabalho nas escolas secundária e normal (18351945)", financiado pelo Conselho Nacional de Desenvolvimento Científico e Tecnológico (CNPq) e coordenado pela professora, Dra . Sílvia Helena Andrade de Brito, cujos membros estão vinculados ao HISTEDBR, da unidade regional de Mato Grosso do Sul. Escolheu-se como marco inicial da pesquisa o ano de 1909, em razão de que nesse momento o ensino normal paulista apresentou uma expansão geográfica significativa, bem como sofreu modificações nos currículos, com especialização de matérias. Como marco final elegeu-se o ano de 1945, dadas as exigências históricas, dentro das quais se delinearam as reformas educacionais e os Decretos-Lei (Leis Orgânicas do Ensino), que balizaram as novas disposições e organização escolar, no governo Vargas. A escolha da Escola Normal de São Paulo como locus da pesquisa decorreu da sua condição de forma mais desenvolvida dessa modalidade de ensino, no período republicano e por ser o espaço onde se consolidou o modelo de ensino público elementar e normal. Trata-se de uma pesquisa que tem como objetivo apreender os manuais na condição de instrumentos didáticos, com foco na alfabetização. Para fins desta fase da pesquisa, buscou-se levantar o estado da arte sobre manuais didáticos voltados à alfabetização, o qual compõe os seguintes trabalhos: estudo analítico de teses e dissertações que investigam a alfabetização, análises de cartilhas e análise de manuais pedagógicos na alfabetização. Assim, o estado da arte apontou aspectos que não foram explorados nessas pesquisas, e que se encontram ainda em aberto para análise. Trata-se da ausência de pesquisas focadas na dimensão histórica e na função que os manuais didáticos cumpriram na formação dos professores alfabetizadores. Assim, busca-se aqui abordar a pesquisa em uma perspectiva histórica, como forma de criar condições para questionar esse instrumento e entender os seus limites para a educação na escola contemporânea.

Palavras-chave: alfabetização, manuais escolares, Escola Normal de São Paulo.

\section{ABSTRACT:}

The present work is part of an ongoing research entitled "Literacy in the Didactic Manuals used in the 'Escola Normal' of São Paulo for the Instruction of the Normalistas"(19091945). The theme and the method are linked to an inter-institutional research, "The Didactic Manual as instrument of Work in the Secondary and Normal Schools (18351945)", financed by the Conselho Nacional de Desenvolvimento Científico e Tecnológico (CNPq) and coordinated by Dra ${ }^{a}$ Sílvia Helena Andrade de Brito, whose members are 
linked to HISTEDBR, in the regional Mato Grosso do Sul unit. We chose as the starting point of our research the year 1909 because at that time the São Paulo 'Normalist' Schools displayed a significant geographical expansion as well as suffering curricular modifications, with the specialization of subjects. The year 1945 was chosen as the concluding date given the historical demands inside which the educational reforms and the legal decrees (Leis Orgânicas do Ensino), which served as the basis for the new educational disposition and organization, were outlined, during the Vargas government. The choice of the Escola Normal of São Paulo as locus of the research occured because of its condition as the most developed within this mode of education during the rebuplican period and also for being the space where the model for elementary and normal state school systems were consolidated. The aim of this research is to aprehend the manuals in their condition as didactic instruments, focusing on literacy. For this phase of the research, we investigated the state of the art on didactic materials geared towards literacy, which comprised of the following tasks: the analitic study of theses and dissertations which investigated literacy, the analysis of the cartilhas and the analysis of pedagogical manuals on literacy. Thus, the state of the art pointed towards aspects which had not been exploited by those researches and are yet to be analyzed. We highlight the absence of researches focused on the historical dimension and on the role fulfilled by the didactic manuals in the formation of literacy teachers. Thus, we strive to approach this research from a historical perspective, as a means of creating conditions for questioning this instrument and understanding its limitations in the contemporary school.

Keywords: literacy, school manuals, Escola Normal of Sao Paulo.

\section{INTRODUÇÃO}

O texto que ora se apresenta compõe pesquisa em andamento intitulada, $A$ Alfabetização nos Manuais Didáticos Utilizados na Escola Normal de São Paulo para a Instrução dos Normalistas (1909-1945). A temática e o método estão vinculados a uma pesquisa interinstitucional1 - O manual didático como instrumento de trabalho nas escolas secundária e normal (1835-1945), que está sendo realizada por professores de diferentes áreas do conhecimento: Biologia, Letras/Literatura, História, Psicologia e Pedagogia.

Elegeu-se como objeto de investigação o manual didático, na condição de instrumento de trabalho na Escola Normal de São Paulo, cuja existência remonta ao ano de 1846. Determinaram-se, como marco temporal da pesquisa, os anos de 1909 a 1945, em razão das mudanças no processo escolar na rede de ensino e na organização do trabalho didático, para responder aos imperativos da universalização do ensino primário.

O marco inicial da pesquisa será o ano de 1909, visto que, segundo Carlos Monarcha, foi, sobretudo, nesse momento que o ensino normal paulista experimentou “(...) um processo de expansão geográfica e de massificação, com modificações no chamado núcleos de estudo pedagógicos, aprofundando-se a especialização das matérias do currículo" (MONARCHA, 1999:238). Conforme o mesmo autor, no curso de sua 
constituição, a Escola Normal passou por processos críticos de fechamento e reabertura, até a consolidação de sua fundação em 1846.

No transcorrer da Monarquia e da República, a Escola Normal de São Paulo ganhou diferentes configurações, com modificações nas suas edificações e em seus currículos. A escola, com existências recorrentes, conseguiu certa estabilidade após 1870, mas foi na última década do século XIX que ela, de fato, se fortaleceu. A marca de sua proposta se configurou na reforma de Caetano de Campos, com a criação da Escola-Modelo, espaço destinado como campo de experimentação de novas práticas de ensino para os normalistas, constituindo-se o centro de aplicação e de irradiação do método intuitivo no ensino primário. Porém, foi somente depois da proclamação da República, que a Escola Normal ganhou, finalmente, plenitude.

Tomou-se como marco final da pesquisa, o ano de 1945, dado que os decretos e as leis2 que balizaram as reformas educacionais, voltados a novas disposições no ensino, no Governo Vargas3, refletiam as adequações necessárias, face ao conjunto das reorganizações no âmbito político-econômico, no Estado brasileiro. Com o pensamento efetivo de uma nova ideologia educacional, as reformas no ensino foram articuladas ao desenvolvimento econômico brasileiro, tendo como base o ideário nacional.

Os decretos que criaram as leis que receberam o nome de Leis Orgânicas do Ensino - e que foram as bases para a organização dos diversos níveis de educação pública - fundamentaram a instituição de um sistema nacional de educação. As reformas efetuadas por Francisco Campos abrangeram o ensino superior, o ensino médio (escolas secundárias e comercial) e a organização do ensino (BRITO, 2006:12)

As reformas empreendidas por Gustavo Capanema, no Estado Novo (19371945), o qual, desde 1934, ocupava a pasta de Ministério de Educação e Saúde, marcou no desenvolvimento da história político-institucional brasileira, um novo conjunto de reformas na educação (Ibid:14). Na reforma Capanema, o ensino secundário, consagrou os objetivos formativos instituídos na reforma de Francisco Campos.

O ensino primário e o ensino normal, também articulados na gestão de Capanema, entraram em vigor em 1946. A Lei Orgânica do Ensino Primário visava, por parte do Governo, à regulação nesse nível de ensino. Segundo Brito (2006) cabia ao Governo Federal fixar os programas mínimos e as diretrizes para o ensino fundamental, e as unidades federadas cumpririam a tarefa de administrar e ainda prover parte dos recursos necessários ao seu funcionamento.

O Ensino Normal, na modalidade de ensino médio, regulado por decreto, versava sobre a formação de professores para o ensino primário, tendo os currículos obrigatórios e os métodos para o desenvolvimento das propostas pedagógicas fiscalizados pelo Governo Federal. Esse período, em um estado de empreendimentos de reformas e Leis que instituem e regulamentam o ensino, justifica-se por buscar o entendimento do papel reservado aos instrumentos didáticos na Escola Normal.

Desde a Independência do Brasil, em 1822, lançou-se a educação como instrumento importante na organização do Novo Estado. Nesse contexto, vislumbra-se a educação escolarizada para o povo, por meio da criação das escolas de primeiras letras. Em razão disso, era necessário haver pessoas habilitadas para ensinar a ler e a escrever. 
A criação da Escola Normal representa, pois, a oportunidade de configurar a institucionalização de cursos de formação de professores para alfabetizar.

A escolha da Escola Normal de São Paulo deve-se, objetivamente, a dois aspectos: primeiro, por sua condição de forma mais desenvolvida dessa modalidade de ensino, no período republicano; segundo, por ser o locus especifico onde se consolidou um modelo de ensino público, especialmente o elementar e o ensino normal, e também por se constituir uma referência para as demais instituições nascentes nas províncias/estados brasileiros.

Entendendo-se que é a partir do mais desenvolvido que se pode apreender o menos desenvolvido, a Escola Normal de São Paulo se inscreveu no interior do referencial teórico-metodológico que impunha tal determinação: a Ciência da História4. São categorias peculiares a essa teoria, o universal e o singular.

Por esse referencial, ilumina-se a reflexão sobre os objetos singulares, mas em uma perspectiva da totalidade, o que implica, no plano teórico, a construção e a reconstrução das partes em relação com o geral. Um pensamento desse porte orienta uma discussão mais profícua para o entendimento do objeto particular, no contexto de sua nascente, na medida em que sua materialização opera na sociedade, a partir de leis mais gerais, em um movimento conflitante, marcado pela contradição.

Os manuais didáticos que hoje têm sua expressão nos modernos livros didáticos, com distintas abordagens teóricas, constituem-se, nas diversas áreas do conhecimento, como fonte de pesquisa em expansão no campo da educação. Nesse sentido considerase necessário elucidar alguns aspectos acerca da sua produção na escola moderna.

\section{A ORIGEM DOS OS MANUAIS DIDÁTICOS}

O manual didático5 tornou-se um instrumento comum, utilizado na escola. Considerando especificamente os destinados ao ensino elementar, pode-se nomear a sua visibilidade desde a publicação da Cartinha6 com os Preceitos e Mandamentos da Santa Madre Igreja, publicada em 1539, com a Gramática da Língua Portuguesa e o Diálogo em Louvor da Nossa Linguagem e Diálogo da Viciosa Vergonha, produzidas por João de Barros7 e publicados em 1540. (ARAÚJO, 2008:8). João de Barros, pelo menos um século antes de Comênio publicar sua obra Orbis Sensualium Pictus8, que trazia lições ilustradas, já utilizava recursos visuais no ensino das línguas9.

Vinte e dois anos antes de Comênio, já havia marcas da pedagogia moderna na obra Escritos sobre A Nova Arte de Ensinar, de Wolfgang Ratke (1571-1635),10 e quarenta e cinco anos antes da edição da Didáctica Magna, de Comênio, o pedagogo alemão, representante do pensamento burguês,

[...] inaugurou a instituição escolar e a didática, com práticas escolares inovadoras à base da divisão do trabalho didático [...]. Dois princípios gerais norteavam o seu pensamento político pedagógico: instrução pública para todas as crianças e instrução coletiva, que resultou na divisão do trabalho didático e na utilização dos manuais didáticos (HOFF, 2008:6-7). 
Embora Ratke tenha elaborado muitos manuais didáticos, "O método geral da didática" foi um dos poucos escritos editados em vida (HOFF, 2008:11). Ratke, como representante da sociedade burguesa, figura na história da educação como crítico do sistema social feudal; ele entendia ser necessário combater aquele pensamento que subtraía das crianças a educação.

$\mathrm{Na}$ transição do feudalismo para o capitalismo, época em que viveram Ratke e Comênio, século XVI e XVII, a educação formal não era do alcance de todos os homens, mas destinava-se a um determinado segmento da sociedade. Não havia uma arquitetura que comportava a educação tal como se apresenta na escola contemporânea, ou seja, não havia um espaço organizado especificamente para o trabalho escolar.

Cabe destacar que o trabalho didático era realizado, predominantemente, pelos preceptores e correspondia à forma de trabalho de um artesão. Assim como o artesão que, com o domínio da sua atividade, desenha, cria e modela sua arte, também os preceptores, eram os homens que tinham um largo conhecimento e dominavam seu conteúdo. Tinham, por excelência, o domínio de sua profissão. Essa forma de organização do trabalho didático, praticada sob o comando da Igreja Católica era voltada para uma elite. Esse modelo de educação era inviável para se pensar na difusão da educação para todos, uma vez que os custos com o preceptor e com os livros eram muito elevados.

Pode ser considerado que as formulações que instituem a idéia de educação para todos se iniciaram com Ratke, o qual via a necessidade de "que todas as crianças fossem instruídas principalmente na leitura, na escrita e no cálculo" (HOFF, 2008:8). Todavia é na obra, a Didáctica Magna, "Tratado Universal de Ensinar Tudo a Todos", publicada em 1657, que se estabelecem as bases do trabalho didático, consolidado na transição do século XIX para o século XX, e ainda mantido na escola contemporânea.

Portanto, é a partir de Comênio que o sistema educativo passou a consagrar o manual didático na escola, com a instituição do ensino coletivo, especialmente com a criação da escola moderna. Inspirado na manufatura11, método de produção material mais avançado da época, Comênio instituiu o ensino coletivo.

Na manufatura, o trabalhador perde o domínio do processo de trabalho em sua totalidade, o trabalho passa a ser dividido e desenvolvido coletivamente, com o uso de instrumentos especializados. Os trabalhadores produziam a mercadoria no mesmo espaço físico e ao mesmo tempo. A manufatura impôs profundas alterações no processo de trabalho.

O trabalho artesanal era complexo, de modo que não permitia a ampliação da produção de excedente, uma exigência imposta pelo desenvolvimento do comércio mercantilista. A divisão do trabalho expressa um aumento significativo da força produtiva dos homens, na medida em que nessa forma de produção, o trabalho se torna uma operação simples em que cada trabalhador, operando em um mesmo espaço e com instrumentos pertinentes, executa parte de um trabalho.

A divisão de tarefas enraizada com o sistema de produção manufatureiro torna o trabalho cada vez mais especializado. E, com o desenvolvimento das tecnologias, o trabalho vai sendo progressivamente objetivado, de modo que os trabalhadores passam 
a se ocupar com uma ou com poucas operações, as quais são crescentemente simplificadas.

O trabalho manufatureiro apropriado por Comênio para oferecer a educação escolarizada favorecia a atividade escolar coletiva por meio do recurso a um instrumento, o manual didático. Com este instrumento, um único professor poderia ensinar um grande número de alunos. Comênio (1996:136) dizia. “[...] na verdade, há uma grande economia de fadiga e de tempo, quando uma só pessoa faz uma só coisa [...] uma só pessoa pode servir utilmente a muitas [...]". Desde então, os manuais passaram a ser amplamente utilizados nas instituições escolares, tornando-se o principal instrumento de ensino. Ilustra-se tal propósito com as palavras de Comênio (1996:430).

A cada classe eram destinados livros de textos próprios, que contenham todo programa prescrito para essa classe (quanto à instrução, à moral e à piedade), para que, durante o espaço de tempo em que os jovens são conduzidos pelo caminho destes estudos, não tenham necessidade de nenhum outro livro12, e com ajuda desses livros possam ser conduzidos infalivelmente as metas fixadas. [...] Portanto, em conformidade com o número de classes, [...] diferentes entre si, não tanto pelas matérias tratadas, como pela forma.

Compondo a idéia de que um único instrumento, com as características que lhe são particulares, permite o trabalho coletivo, o educador morávio adotava livros de textos próprios, instrumento que permitia a objetivação do trabalho do professor.

"[...] aos educadores da juventude é necessário dar normas, em conformidade com os quais executem as suas obras, isto é, devem inscrever-se para uso deles livros-roteiros que os aconselhem quanto ao que hão-de fazer, em que lugar e de que modo, para que não se caia em erros. Os livros didácticos serão, portanto, de dois gêneros: verdadeiros livros de textos para os alunos, e livros-roteiros (informattori) para os professores, para que aprendam a servir-se bem daqueles (COMÊNIO, 1996:460).

Trata-se de criar as condições objetivas para superar as limitações impostas para fundar a escola para todos. Porém, ainda hoje, apesar dos avanços tecnológicos, os manuais subsistem de forma preponderante na sua função de mediação e de transmissão dos conhecimentos.

Partindo do pressuposto de que o manual permanece na escola contemporânea e tem centralidade como instrumento didático, com a atenção voltada para os processos do ensino da leitura e da escrita, a questão que se coloca é: de que forma a alfabetização aparece nos manuais didáticos, utilizados na Escola Normal de São Paulo, para oferecer aos alunos normalistas as bases para ensinar às crianças a leitura e a escrita?

Nessa perspectiva, a categoria organização do trabalho didático, na acepção formulada por Alves (2005:10-11), tem os aspectos que contribuem para analisar historicamente o sistema escolar e para tomar o objeto em estudo na sua particularidade.

No plano mais genérico e abstrato, qualquer forma histórica de organização do trabalho didático envolve, sistematicamente, três 
aspectos: a) Ela é, sempre, uma relação educativa que coloca, frente a frente, uma forma histórica de educador, de um lado, e uma forma histórica de educando (s), de outro. Realiza-se com a mediação de recursos didáticos, envolvendo os procedimentos técnico-pedagógicos do educador, as tecnologias educacionais pertinentes e os conteúdos programados para servir ao processo de transmissão do conhecimento, e implica um espaço físico com características peculiares, onde ocorre.

Desse modo, interessa analisar as formas que esse instrumento assumiu no domínio do aparelho escolar, de modo a revelar sua natureza histórica e o seu lugar na organização do trabalho didático. De um lado, a intenção é evidenciar as características dos conteúdos veiculados pelo manual didático e, de outro lado, apreender as funções por ele assumidas na relação educativa; sendo assim é importante apreender as especificidades desse instrumento de trabalho na escola normal.

O esforço para o estudo parte do entendimento de que esse instrumento muito nos revela sobre como se pensou e produziu a educação frente às condições de sua época. Nessa perspectiva, busca-se encontrar, na história, a raiz de sua constituição e de sua contribuição no seu tempo.

Nesse sentido, o professor Gilberto Luiz Alves, - um pesquisador deste objeto13 - pontua que os estudos sobre os manuais têm sofrido historicamente de uma mesma problemática: na condição de instrumentos de trabalho do professor são vistos como "coisa", isto é, são abstraídos das relações sociais e históricas em que foram produzidos. Essa visão limita a compreensão dos instrumentos didáticos, situados historicamente, como elemento substantivo na formação dos alunos e, em decorrência disso, limita a superação de determinados instrumentos.

O fato implica colocar o objeto no contexto histórico mais amplo, visto que sua consolidação é regida a partir de leis mais gerais da sociedade em que se inscreve. Portanto, fundamentado numa concepção de história, procura-se compreender como a alfabetização é tratada nos manuais escolares na Escola Normal, durante o período de 1909-1945, na formação/instrução dos normalistas.

Considerando que a Escola Normal de São Paulo é o locus da pesquisa, e que o marco temporal está localizado nos anos que vão de 1909 e 1945, faz-se necessária uma pequena incursão aos antecedentes históricos do ensino normal em São Paulo. Busca-se reconstituir as idéias e demandas que foram sendo forjadas no período imperial e republicano, com o objetivo de expansão do ensino primário, de forma que se possa compor uma visão de conjunto daquele contexto histórico e dos aspectos socioeconômicos refletidos na educação naquela época, na constituição do ensino primário e da escola normal para a formação dos normalistas.

\section{ALGUNS ANTECEDENTES HISTÓRICOS DO ENSINO NORMAL EM SÃO PAULO.}

A Independência (1822) marca o surgimento de uma nova nação e, como decorrência, a necessidade de o novo país organizar-se como Estado. Com efeito, ao lado da composição da Assembléia Nacional Constituinte e Legislativa, anuncia-se a necessidade de se criar uma legislação especial para a instrução pública, o que coloca 
em debate um projeto para a organização de um sistema de escolas públicas para ser implantado em todo o território do novo Estado.

Ao lado de divergências políticas, em meio a antagonismos e contradições, em 1827 é aprovada a primeira Lei sobre a instrução no Brasil14 que cria e regula o funcionamento das Escolas de Primeiras Letras. Se tivesse atingido seu propósito, essa Lei teria dado origem à construção de um projeto de um sistema nacional de instrução pública. Contudo, na prática, não foi o que se concretizou.

De fato, o Governo Central, ao inserir à Constituição do Império o Ato Adicional de 12 de agosto de 1834, sob a égide da descentralização, desobrigou-se de cuidar das escolas primárias e secundárias, conferindo às Assembléias Legislativas Provinciais, entre outras atribuições, a de legislar sobre a instrução pública. Segundo Tanuri (1979), a abstenção do poder central colocou as Escolas Normais, bem como os demais estabelecimentos de nível primário, sujeitos à penúria financeira dos cofres provinciais. Todavia, Saviani esclarece que, ao longo do período imperial, os relatórios dos ministros e dos presidentes de províncias evidenciam as carências do ensino, o que permite concluir que o Ato Adicional de 1834 apenas legalizou a omissão do poder central nessa matéria. (SAVIANI, 2005:129).

Pode-se afirmar, no entanto, que, relacionadas ao Ato Adicional de 1834, as primeiras Escolas Normais brasileiras foram fundadas por iniciativas das províncias, em datas seqüentes: em 1835, no Rio de Janeiro em Niterói, na Bahia (1836), no Pará (1839), em Minas Gerais (1840) e no Ceará (1845), oferecido em cursos públicos de nível secundário15, visando formar professores para atuarem no magistério de ensino primário.

Em 1846, fundou-se a Escola Normal de São Paulo16 - a primeira a regulamentar de modo geral todo o ensino primário na Província Paulista. Em sua trajetória histórica, essa escola, "cuja origem e desenvolvimento vincula-se à difusão dos ideais liberais17 de secularização e expansão do ensino primário," (TANURI, 1994:41) mudou várias de nome e de edifício e sofreu alterações em seu currículo. Marcada por fechamentos e reaberturas até 1880, na organização didática oferecia uma rudimentar formação pedagógica, e era limitada em conteúdo ao plano de estudos das escolas primárias.

Contudo, na primeira metade do século XIX, no âmbito do Ministério do Império, os debates e projetos de reforma da instrução pública tornam-se constantes. Em 185418, o Ministro do Império19 baixou o Decreto n 1.331-A, de 17 de fevereiro, estabelecendo o regulamento para a reforma do ensino primário e secundário do Município da Corte. Esse documento delineava os instrumentos legais para regimentar a instrução pública, versando sobre condições para o magistério público [...] (LIMEIRA e SCHELBAUER, 2008: 34).

Destaca-se que um dos regulamentos20 desse documento dizia respeito à substituição das Escolas Normais pelo professor adjunto. Por meio de concurso geral aberto, os aprovados ficariam adidos às escolas como ajudantes e aprendizes nas matérias de práticas de ensino e nessa condição passariam por um "triênio de habilitação". 
No entanto, apesar de os dispositivos do documento dessa Reforma servirem como referência para a instrução pública em muitas províncias, os vários outros projetos apresentados ao Parlamento, nos anos subsequentes ao Regulamento de 1854, mostraram a sua pouca efetividade prática, especialmente no que dizia respeito à substituição das Escolas Normais pelos professores adjuntos. As Províncias movimentam-se no esforço de criar Escolas Normais e, à exemplo disso, a própria Escola Normal de Niterói, fechada por Couto Ferraz em 1849, foi reaberta em 1859.

As reformas prosseguiam, assumindo, porém, novos contornos na década de 1860, quando a pasta de Ministro do Império foi ocupada por José Liberato Barroso que deu prioridade às questões da instrução pública. As reflexões de Liberato Barroso foram reunidas num livro A instrução pública no Brasil, publicado em 186721, obra que, segundo Saviani (2005), pode-se dizer ter inaugurado a fase final do Império.

A economia brasileira, em meados do século XIX, seguia baseada no modelo denominado de agrário-comercial exportador, sendo a produção do café a sua principal forma de sustentação. As condições da época, a demanda externa e nossas terras favoráveis para o cultivo desse produto, contribuíram para o bom desenvolvimento dos negócios de importação/exportação, o que permitiu aos produtores e comerciantes do café uma acumulação de capital. No entanto, já no final do século XIX e início do século XX, esse modelo de economia dava mostras de esgotamento. O capital acumulado durante o desenvolvimento da cafeicultura criou as condições para que a produção manufatureira ganhasse força. Foi dessa forma que as primeiras indústrias se instalaram no país.

No âmbito político, as forças representadas pela classe latifundiária e pela "jovem" burguesia industrial que surgia passaram a disputar espaço nas decisões do Estado. O ideário positivista22, importado da Europa conduziu a maneira de pensar e de empreender as ações voltadas para a sociedade em geral, como, por exemplo, aquelas ligadas ao campo da educacional.

É neste quadro que chega ao fim o período do Império e tem início a República no Brasil. Para atender às novas necessidades de educação, surgiu um novo regime e os representantes desse novo regime "(...) procuram modificar a relação entre governados e governadores, a fim de assegurar a autoconservação desse novo sistema. Pensa-se na educação não como condição de ascensão social, mas como condição prévia para o bom funcionamento das instituições republicanas". (MONARCHA, 1999:171).

O Decreto $\mathrm{n}^{\circ} 27$, de 12 de março de 1890, inaugurou a marca republicana no âmbito das políticas públicas. A Reforma da Escola Normal Paulista foi conferida à administração de Antonio Caetano de Campos, cuja tarefa era implantar inovações visando à Reforma Geral da Instrução Pública do Estado de São Paulo. Entre as reformas efetuadas nas escolas normais, a de Caetano de Campos, em 1890, “[...] foi aquela que representou alteração significativa no ideal de formação prática do professor. Além disso, acenou para o universo feminino a oportunidade de instruir-se e educarse23", uma vez que a Escola Normal, criada em 1846, destinava-se às pessoas do sexo masculino.

Embora tivesse permanecido menos de dois anos na direção da Escola Normal, Caetano de Campos tem seu nome ligado à história de todo Ensino Normal no Estado 
de São Paulo (ALMEIDA, 1995:09). Foi na reforma de Caetano de Campos que se instituiu a "Escola Modelo" como um campo de prática de ensino, reservada aos normalistas para exercitar, na prática, a teoria. "Escola-Modelo" traduzia a contribuição teórico-metodológica nos moldes do "aprender a aprender fazendo" proposto por Comenius e Pestalozzi. (ALMEIDA, 1999).

Nesse momento, o intuito era consolidar as mudanças pedagógicas e, com bases nos métodos de ensino renovado, desenhar para as escolas normais um currículo centrado na prática dos professores. Na marcha do método intuitivo, alçava-se a figura de um "professor ou professora-modelo", versados em um profundo conhecimento do método e da sua disciplina, ministrando "aulas-modelo" (ALMEIDA, 1995:09). Foi na reforma de Leôncio de Carvalho que os princípios do ensino intuitivo foi instituído pela primeira vez na legislação educacional do Império.

Preconizado através das Noções de coisas, como disciplina do ensino nas escolas primárias do $1^{\circ}$ Grau e Prática do Ensino intuitivo ou lições de coisas, como disciplina do programa de ensino das Escolas Normais do Estado24 (SCHELBAUER, 2003:87). "Em meados do século XIX, o método intuitivo é entendido por seus propositores europeus e americanos como instrumento pedagógico capaz de reverter a ineficiência do ensino escolar [...]" (VALDEMARIN, 2004:103). Num clima de renovação pedagógica, que começava a despontar nesse período, "[...] a chave para desencadear a pretendida renovação é a adoção do ensino intuitivo" (VALDEMARIN:104), também divulgado sob a expressão lições de coisas, considerada por Buisson25 "[...] como a primeira forma de intuição: a intuição sensível”. (SCHELBAUER, 2003:31).

A observação e a experimentação deveriam ser exploradas para desenvolver a percepção sensível em substituição à memorização dos livros textos. "A aprendizagem passaria agora pelo sentido, fazendo coisas" (SCHELBAUER, 2003:14). Nesse processo, o livro passa a ser menos utilizado pelo aluno, em função do emprego de outros materiais didáticos. Mas, para o professor, o livro torna-se instrumento base que orienta toda a prática pedagógica, expondo um modelo de procedimentos para a elaboração de atividades escolares, constituindo-se manuais didáticos que passaram a ser o guia diretor para que as inovações pudessem ser efetivadas.

\section{A ALFABETIZAÇÃO NOS MANUAIS ESCOLARES: O ESTADO DA ARTE}

Com o objetivo de conhecer o estado da arte da temática proposta para estudo, inicia-se o levantamento do que já foi ou do que está sendo produzido em relação à alfabetização vinculada aos estudos dos manuais didáticos. Os primeiros contatos estão sendo estabelecidos através da produção da história e da historiografia por meio de artigos, livros, teses, dissertações e revistas brasileiras de educação.

Não se tem, nesse momento, a intenção de realizar um estudo exaustivo sobre o assunto, mas buscam-se os primeiros apontamentos com o intuito de sistematizar as investigações já desenvolvidas sobre o estudo dos manuais didáticos. Assim, para fins desta fase da pesquisa, buscou-se levantar o estado da arte sobre os manuais didáticos voltados à alfabetização, o qual compõe os seguintes resultados: estudo analítico de teses e dissertações que investigam a alfabetização, análise de cartilhas e análises de 
manuais pedagógicos na alfabetização os quais, didaticamente organizados, serão descritos por suas características.

Com relação ao estudo analítico de teses e dissertações, segundo Peres (2008), na produção acadêmica acerca da alfabetização, Magda Soares e Francisca Maciel (2001) realizam o estudo, "A alfabetização no Brasil: o estado do conhecimento (1961-2001)", apontam que ainda são poucas as investigações sobre a alfabetização em uma "perspectiva histórica". Sobre esse aspecto apontam a existência de seis trabalhos26. Segundo a mesma autora, Maciel (2003) em um levantamento das comunicações e conferências realizadas em congressos27 de História e Educação identificou, até 2003 dez trabalhos voltados para a alfabetização em uma perspectiva histórica. Os trabalhos apresentados como resultados dessas pesquisas são agrupados por Maciel em dois eixos: os métodos de leitura e de escrita e os manuais "escolares", as cartilhas.

Como exemplo de pesquisa, nessa abordagem, anuncia-se a tese de livre docência de Maria do Rosário Longo Mortatti (2000) que resultou na publicação do livro: "Os sentidos da alfabetização“. Como recorte temporal inicial, foi eleito o período de 1876, ano de publicação da Cartilha Maternal, de João de Deus, e como marco final, 1994, ano de mudanças na política educacional paulista e brasileira. Como recorte espacial, o estudo incide sobre a província do Estado de São Paulo, pelo papel desempenhado na organização do sistema público de ensino no Brasil. A pesquisadora recuperou um farto conjunto de fontes, o que coloca sua produção no bojo de pesquisas desenvolvidas com manancial bastante amplo da história da alfabetização no Brasil.

Magda Soares (1999) caracteriza, na apresentação do livro, três razões que atribuem à obra de Mortatti (2000) um patamar de importância: primeiro, porque aborda a ausência de estudos históricos nessa área em educação no Brasil; segundo, porque ela reconstitui a história dos métodos de ensino da leitura e escrita - a história dos sentidos que, ao longo do tempo, foi sendo atribuída à alfabetização - aspectos que têm polarizado as discussões e intervenções na área de alfabetização; e, terceiro, por representar uma laboriosa, persistente e paciente seleção de fontes recolhidas, instrumentos que permitiram à pesquisadora alicerçar seus estudos, recuperando os processos do passado que foram forjando e construindo as polêmicas e os métodos ao longo dos tempos.

Mortatti (2000) sistematiza seu estudo, abordando os problemas da leitura e da escrita. Segundo a autora, os sentidos da alfabetização lhe foram sendo atribuídos em decorrência das tematizações, normatizações e concretizações produzidas nesse período na província paulista, do qual ela reconstitui a história dos métodos da leitura e da escrita na fase inicial de escolarização das crianças. Mortatti (2000) dialoga na sua abordagem com o problema da alfabetização e com as tendências nas últimas décadas entre os pesquisadores europeus e americanos e que tem avançado entre os pesquisadores do Brasil.

Quanto às pesquisas concernentes aos manuais didáticos, no caso da alfabetização traduzidas nas cartilhas, em 2003, Ceris Salete Ribas da Silva defendeu a dissertação: As repercussões dos novos livros didáticos de alfabetização na prática docente, na Universidade Federal de Minas Gerais, Faculdade de Educação. Segundo a pesquisadora, os critérios do Governo Federal para a avaliação do livro didático 
estabelecem que as atuais propostas de alfabetização representam um novo corpus de conhecimento sobre o ensino da língua escrita.

A matriz teórica que baliza esses critérios se configura com a perspectiva "construtivista ou interacionista", caracterizando as antigas propostas didáticas como símbolo dos métodos tradicionais de ensino. A partir desses critérios, a autora analisa as práticas de ensino de escolas que adotaram os livros didáticos de alfabetização avaliados nos Planos Nacional do Livro Didático, nos anos de 1998 e 2000, e que tiveram os melhores conceitos.

O eixo e a análise das investigações incidem sobre o processo de apropriação, pelos professores, da "nova" proposta pedagógica. Para subsidiar a análise, a pesquisadora adotou o conceito de transposição didática. A questão central foi desvendar como se desenvolviam as ações e o modo de refletir dos professores, quando da programação das novas propostas dos livros didáticos de alfabetização adotados.

Para esse estudo, os dados foram coletados em seis escolas e se desenvolveram em duas etapas. Como instrumentos de trabalho, utilizaram-se questionários padronizados com questões fechadas e abertas para captar aspectos relevantes para a pesquisa. Obtiveram-se, como resultado, diferentes perspectivas de compreensão da noção de qualidade dos livros didáticos, elaborados num cenário de burocracia governamental (e no universitário que, para o Governo, presta seus serviços), editorial e escolar.

Solange Aparecida de Oliveira Collares28 (2008) também faz a análise de cartilhas. Em dissertação de mestrado, desenvolveu a pesquisa: "História da cartilha progressiva (1907) nas escolas do Estado do Paraná29”, na Universidade Estadual de Ponta Grossa. Para a condução do estudo, a pesquisadora considerou a ideologia como categoria fundamental para a análise da sociedade e, como princípio educativo, mediador das relações entre os homens, determinando as formas de organização social, política e jurídica.

Para estabelecer a relação ideologia-educação, no âmbito das cartilhas, a autora considerou necessária a análise do objeto em estudo sob a perspectiva histórica, balizada na concepção de Marx. O objetivo foi analisar em que contexto social e político havia surgido a cartilha utilizada nas escolas primárias do Estado do Paraná, para a instrução da leitura e da escrita. O manual de leitura em análise foi a "Cartilha Progressiva", de autoria de Lindolpho Pombo30, editada pela primeira vez em 1900, tendo sido utilizada até 1907 pelas escolas públicas e particulares do Paraná. Especificamente, buscou analisar a primeira cartilha paranaense de alfabetização, bem como seu surgimento e sua importância, e investigar a concepção pedagógica do autor na cartilha progressiva.

A escolha desse estudo foi motivada pela necessidade de verificar a influência desse material que contribuiu na formação de pessoas no início da Primeira República na educação. Como resultado, observou, nesses manuais de leitura, a imposição de valores e a manipulação da conduta moral e cívica com o objetivo de naturalizarem o enquadramento dos comportamentos sociais que demonstra uma clara intencionalidade do ensino e dos conteúdos que em tempo algum permaneceram neutros às imposições ideológicas e sociais a época. 
Em 2001, Vivian Batista da Silva31, na Faculdade de Educação da Universidade de São Paulo, defendeu o estudo: Uma história das leituras para professores: análise da produção e circulação de saberes especializados nos "manuais pedagógicos" (1930-1971). Para essa pesquisa, selecionou quarenta e quatro títulos de livros escritos para uso em escolas normais, nas disciplinas relacionadas diretamente a questões educacionais: pedagogia, didática, metodologia e prática de ensino.

Informa a pesquisadora que o recorte inicial (1930) considera as mudanças impelidas nas escolas normais de vários estados do Brasil e também em função do aumento de publicações destinadas aos futuros professores. O marco final (1971) devese à promulgação da Lei de Diretrizes e Bases (LDB) $n^{\circ} 5692$, que substitui as antigas instituições pela habilitação para o Magistério e, ainda, pela sofisticação dos recursos tipográficos, o que marca a distinção da maior parte das obras publicadas no país durante esse período.

A pesquisadora examinou algumas das características dessa produção e o modo pelo qual o conjunto de textos constrói e divulga os saberes sobre o oficio do docente. Sobre as tendências evidenciadas nos manuais entre os anos de 1930 e 1971, a pesquisadora sistematizou as mudanças da seguinte forma: nos anos de 1930 a 1946, o entusiasmo pelo movimento escolanovista; entre 1947 e 1959, a proposição de metodologias de ensino; e entre os anos de 1960 a 1971, a apresentação das tecnologias a serviço da eficiência das atividades pedagógicas.

Vale destacar, ainda, no âmbito da pesquisa sobre os manuais, utilizados para formação de professores, o trabalho conjunto de Vivian Batista da Silva e Antonio Carlos Luz Correa, da Universidade de Lisboa, num amplo projeto em que realizam pesquisas sobre a gênese do desenvolvimento escolar do modelo escolar no século XIX, no qual examinam o manual pedagógico na construção da identidade do professor em Portugal e no Brasil no período de 1930 a 1970. Procuram, também, identificar os modos pelos quais as informações foram construídas e divulgadas em livros escritos para cursos de formação de professores.

A pesquisadora Vivian Batista da Silva (2006)32 em outro artigo Saberes em viagem nos manuais pedagógicos: construções da escola em Portugal e no Brasil (1870-1970) procura construir a história comparativa dos manuais pedagógicos editados no Brasil e em Portugal. O estudo concentra-se no período que vai de 1870 - ano em que foram publicados os títulos mais antigos - até 1970, momento em que são introduzidas "novas técnicas editoriais" (fotos, ilustrações, capas coloridas, letras maiores), as quais geram outras práticas de leitura.

A autora esclarece que foi nesse momento que os manuais passaram a ser utilizados para realizar estudos acerca do "ofício de ensinar", junto às disciplinas de Pedagogia, Didática, Metodologia e Prática de Ensino. Adotando a perspectiva teórica das "disciplinas escolares" (cultura escolar), Silva (2006:1) informa que pretende averiguar no artigo, em que medida os "livros dos normalistas" contribuíram para a efetivação de um modelo de escola conhecido em vários lugares do mundo, pois, segundo ela (2006:1) a "história dos manuais articulou-se à difusão da escola e dos conhecimentos pedagógicos". 
Os livros da Escola Normal, afirma a autora, foram produzidos no período de constituição dos sistemas de ensino públicos, obrigatórios, gratuitos e organizados pelo Estado. Para desenvolver a pesquisa a autora catalogou oitenta títulos de manuais pedagógicos (livros dos normalistas), sendo vinte e cinco portugueses e cinquenta e cinco brasileiros e, selecionou dez para análise, no referido texto.

Conforme a pesquisadora, os manuais pedagógicos, que circularam tanto em Portugal como no Brasil, tiveram como objetivo divulgar uma forma de ensinar, ou seja, produziram uma espécie de "gramática do magistério". Vivian Batista da Silva conclui o seu artigo explicando os três marcos que caracterizam os manuais portugueses e brasileiros analisados: 1) os manuais foram escritos para uso dos professores que trabalham no nível elementar da escolarização básica; 2) o marco da história dos manuais pedagógicos nos dois países coincide com o movimento da Escola Nova (décadas iniciais do século XX) e, 3) os manuais passam a expressar o processo de "tecnicização do ensino", privilegiando "argumentos mais sintéticos e prescritos" a respeito do processo de ensino.

Carlota Boto (2007)33, no artigo A arte de tornar ciência o ofício de ensinar: compêndios pedagógicos de Augusto Coelho, investiga os princípios teóricos e metodológicos dos manuais de ensino produzidos pelo pedagogo português José Augusto Coelho (1850-1925). Conforme Boto, o pensador Augusto Coelho é considerado um expoente da pedagogia denominada científica. Ele é autor de vários compêndios (tratados de pedagogia) voltados para a "interpretação do fenômeno educativo e dirigidos principalmente para a formação de professores" das escolas normais $(2007: 1)$.

Os preceitos educativos expostos nos tratados de pedagogia produzidos nessa época, afirma Boto, para atingir o patamar de cientificidade, eram relacionados às outras ciências contíguas, como a psicologia, a biologia e a sociologia. Boto, para desenvolver o seu estudo analisou um conjunto de obras produzidas por Augusto Coelho. Nos escritos de Augusto Coelho, o ensino assume o caráter de ciência, deixando de ser considerado como uma arte. Boto (2007:6) esclarece que, ao procurar tornar a "educação uma ciência exata adequada ao seu meio", o pedagogo português adota uma perspectiva evolucionista inspirada no pensador inglês Charles Darwin. A inspiração positivista é uma marca característica das produções de Coelho que, em1891, escreveu um manual denominado "Princípios de pedagogia" (tomos I a IV), editado no Brasil, considerada por Boto a obra primordial deste pedagogo.

A autora (2007:14), ao concluir a análise das obras de Augusto Coelho, esclarece que o trabalho do pensador português é minucioso, intercalando estudos de caráter filosófico e psicológico com a abordagem de temas relacionados à "materialidade" da escola, como a distribuição de livros, as condições dos prédios escolares para atender às necessidades de aprendizagem dos alunos, o mobiliário escolar e a gestão das verbas públicas. Carlota Boto segue a orientação dos pesquisadores filiados à concepção teórica das "disciplinas "escolares".

Wojciech Andrzej Kulesza (2008), no texto Manuais pedagógicos e formação docente no Brasil (1880-1940) busca analisar a circulação dos manuais didáticos nas escolas brasileiras, tendo como baliza temporal para investigação os primeiros tempos de consolidação da Escola Normal até 1939, momento da ordenação legal do Curso de 
Pedagogia. O foco central de Kulesza é verificar quais eram as ciências que os autores tomavam como referência para elaborar a sua concepção de pedagogia.

Para realizar esta tarefa, ele segue as orientações da "história das disciplinas escolares", fundamentada nas idéias de Chervel (1990). O estudo de Kulesza (2008:2) se detém, em especial, no levantamento e na análise dos materiais didáticos utilizados na Escola Normal da Paraíba, desde 1886 (ano em que começaram a funcionar efetivamente a Escola Normal daquele Estado) até 1940, quando, conforme ele, se "firma a homogeneização dos materiais, currículos e programas" no país, em decorrência da centralização da educação e de condicionantes econômicos.

A disciplina de Pedagogia, voltada especificamente para a formação profissional do normalista, foi instituída, segundo o autor, na Escola Normal de Paraíba, desde 1884, quando ela foi concebida. A reforma dessa Escola Normal em 1917 e 1930, prevendo a sua modernização, instituiu as cadeiras de "Pedologia e Psicologia" e de "Didática do Ensino Primário", além providenciar a sua transferência para um prédio grandioso, acrescenta o pesquisador.

No que se refere aos manuais pedagógicos, Kulesza (2008:6-9) relata o levantamento que tem feito nas bibliotecas públicas e particulares da região da Paraíba, para catalogar esses materiais didáticos. Ele destaca dois autores locais que produziram manuais pedagógicos destinados às escolas normais. São eles: Monsenhor Pedro Anísio Dantas Bezerra (Tratado de Pedagogia, Compêndio de Pedologia e Pedagogia Experimental) e Padre Carlos Leôncio (Manual Teórico-Prático para uso dos educadores).

Isabel Cristina Alves da Silva Frade e Francisca Isabel Pereira Maciel realizaram uma pesquisa intitulada "A história da alfabetização nas cartilhas escolares: práticas pedagógicas, produção e circulação em Minas Gerais", desenvolvida no Centro de Alfabetização, Leitura e Escrita (CEALE)34. Nessa pesquisa, analisaram as cartilhas que circularam no Estado de Minas Gerais, no período de 1834 a 1997, com o objetivo de contribuir para a produção de uma história do ensino da língua materna no Brasil, e para o desenvolvimento de pesquisa de fundo histórico em alfabetização, procurando resgatar a história da alfabetização em Minas Gerais, particularmente as práticas pedagógicas voltadas para o ensino da leitura e da escrita.

E, como estudo que se coloca como balizador no que se refere aos manuais, neste texto merecem destaque os trabalhos da professora Vera Teresa Valdemarin, em especial, "Estudando as Lições de Coisas (2004)". Nessa tarefa, Valdemarin teve como objeto de estudo os manuais de "lições de coisas". Esta obra apresenta aos educadores brasileiros a análise dos manuais didáticos, produzidos no período do final do século XIX, para uso de alunos e professores, para a aplicação do método intuitivo.

Nesse estudo, a autora contempla a análise do manual americano, Primeiras lições de coisas, de Norman Allison Calkins35, os manuais elaborados por Jules Paroz, Saffray e os manuais criados pelo casal Fanny e Michel Delon, adotados nas escolas brasileiras. A pesquisadora insere os manuais didáticos no âmbito de estudos da cultura escolar que, segundo ela, dada a sua abrangência, pode ser tematizada a partir de inúmeros elementos e facetas. 
Tomando os manuais didáticos elaborados como os instrumentos que orientam a prática dos professores, a autora busca pontuar os princípios educacionais vinculados a uma teoria do conhecimento humano. Busca examinar a influência das teorias filosóficas na formulação de procedimentos didáticos, para apreender o modo pelos quais as teorias sobre o conhecimento são convertidas em prescrições metodológicas, para ensinar indivíduos específicos.

Em resumo, ela busca estabelecer a relação entre método de conhecimento e método de ensino. Nessa ótica, procura esmiuçar aspectos da relação que se estabelece entre concepções teóricas e procedimentos didáticos ou entre filosofia e seus desdobramentos educacionais. Assim, dialogando com o contexto histórico em que emergem tais elaborações, seu estudo prioriza a influência de paradigmas epistemológicos nos procedimentos didáticos. Isto significa que seu intuito foi o de debater o papel que a escola tem desempenhado na construção da cultura escolar, com ênfase nos aspectos filosóficos, norteadores das prescrições sobre "o que e como ensinar", que se consubstanciam no processo de transposição didática.

Concluindo este trabalho, vale destacar a importância do estado da arte. O contato com as pesquisas já desenvolvidas é uma referência para o pesquisador, pois, como já foi mencionado anteriormente, além de remetê-lo para momentos fundamentais da história da educação, também lança, por um lado, a perspectiva de que os limites para as investigações estão ainda muito longe e por outro, indica, para o pesquisador, os limites das outras já realizadas, ou seja, deixa claro que há ainda muitos aspectos não explorados, abertos para análise e reflexão. Nesse sentido, considera-se, a ausência de pesquisas focadas na dimensão histórica e na função que os manuais didáticos cumpriram na formação dos alfabetizadores. Assim, busca-se abordar a presente pesquisa em uma perspectiva histórica, como forma de criar as condições para questionar esse instrumento e entender os limites para a educação na escola contemporânea. O próximo passo do estudo é o acesso aos manuais didáticos utilizados na Escola Normal de São Paulo e a sua recuperação, com vistas à análise bem detalhada.

Para finalizar, é importante ressaltar que se pretende, a partir deste estudo, colaborar com a produção de conhecimentos sobre a alfabetização na história da educação brasileira. Espera-se, também, fortalecer a pós-graduação e ainda contribuir para o aumento de documentos e informações que serão gerados.

Tendo como pressuposto que a ciência é uma produção histórica, ou seja, que ela constitui o resultado do trabalho desenvolvido pelos homens, em diferentes épocas, para atender a necessidades concretas, partiu-se do princípio que, para compreender, nos tempos atuais, a questão do livro didático no ensino médio é fundamental fazer uma análise da produção, disponível nas bases de dados, no intuito de conhecer as diferentes abordagens teórico-metodológicas. Assim, então, será possível estabelecer diálogo com os autores e fazer o contraponto com a perspectiva de investigação escolhida.

\section{REFERÊNCIAS}

ALMEIDA, Jane Soares de. Currículos da escola normal paulista (1846-1920): revendo uma trajetória. [On Line], R. Brás. Estudos Pedag.; Brasília v. 76, n 184, p. 665-689, set/dez 1995. 
ALVES, Gilberto Luiz. O trabalho didático na escola moderna: formas históricas, Campinas, SP: Autores Associados, 2005. (Coleção Educação Contemporânea).

BRASIL. Decreto n ${ }^{\circ} 1.131$ - A de 17 de Fevereiro de 1854. Tomo 17, Parte 2 ${ }^{\mathrm{a}}$, Secção $12^{\mathrm{a}}$. [On Line]. Aprova o regulamento para a reforma do ensino primário e secundário no município da Côrte.

BOTO, Carlota. A arte de tornar ciência o ofício de ensinar: compêndios pedagógicos de Augusto Coelho. ANPED, 30ª Reunião Anual/2007, GT 02. Disponível em <http:// www.anped.org.br $>$. Acesso em 10/junho/2009.

BRITO, Silvia Helena Andrade de. A Educação no Projeto Nacionalista do Primeiro Governo Vargas (1930-1945). Navegando na História da Educação Brasileira, HISTEDR (1986-2006), Faculdade de Educação, UNICAMP. Disponível em http://www.histedbr.fae.unicamp.br/navegando/artigos_frames/artigo_101.html. Acesso em 13/04/2010.

COLLARES, Solange Aparecida Oliveira de. História da Cartilha Progressiva (1907) nas Escolas do Estado do Paraná. Dissertação de Mestrado - Universidade Estadual de Ponta Grossa - UEPG - Faculdade de Educação, 2008.

COMÊNIO, João Amós. Didática Magna: Tratado da Arte de Ensinar Tudo a Todos. Introdução, tradução e notas, Gomes, Joaquim Ferreira, $4^{\mathrm{a}}$ edição, Fundação Calouste Gulbenkian. Texto latino, tomo I das Opera Didactica (VER) Omnia, edição da Academia Scientiarum Bohemoslovenica, Praga,1996.

COMTE, Auguste. Discurso preliminar sobre o conjunto do positivismo. São Paulo: Nova Cultural, 1996. (Série os Pensadores).

CORREIA, Antonio Carlos da Luz e SILVA, Vivian Batista da. Uma história de leitura para professores, manuais pedagógicos, formação docente e construção de identidades profissionais em Portugal e no Brasil (1970-1970). [On Line], extraído em 02 de abril de 2009. <http://www.alb.com.br/anais14/Cohilile/H011.doc>.

Escola normal no Estado de São Paulo: de seus primórdios até 1930. In: REIS, Maria Candido Delgado (Org.). Caetano de Campos: fragmentos da história da instrução pública no Estado de São Paulo. Acesso em 10 de Abril de 2010, disponível em:<www.histedbr.fae.unicamp.br/navegando/fontes_escritas/3_Imperio/1846_escola_normal>

FERREIRA, António Gomes e FELGUEIRAS, Margarida Loureiro. Livros para o ensino primário: a relevância das primeiras leituras. $\mathrm{O}$ manual escolar como fonte historiográfica. In: Manuais escolares da Biblioteca Pública Municipal do Porto. Universidade do Porto. Catálogo da exposição na B.P.M.P., VII Congresso Luso-Brasileiro de História da Educação, Cultura escolar, Migrações e Cidadania, jul/2008.

FRADE, Isabel Cristina Alves da Silva e MACIEL, Francisca Isabel Pereira. A história da alfabetização nas cartilhas escolares: práticas pedagógicas, produção e circulação em Minas Gerais (1834-1997). [On Line], Centro de Alfabetização de Leitura e Escrita CEALE.

KULESZA, Wojciech Andrzej. Manuais pedagógicos e formação docente no Brasil (1880-1940). VII Congresso Luso-Brasileiro de História da Educação/2008. Disponível em $<$ http://www.web.letras.up.pt>. Acesso em 12/outubro/2009.

LIMEIRA, Aline de Morais e SHUELER, Alessandra F. Martinez de. Ensino particular e controle estatal: a reforma de Couto Ferraz (1854) e a regulação das escolas privadas 
na Corte Imperial. [On Line] Revista HISTEDBR, Campinas nº 32, p. 48-64, dez/2008, ISBN 1676-2584.

MARX, Karl. \& ENGELS, F. A Ideologia Alemã: Feuerbah. 5. ed. São Paulo: HUCITEC, 1986.

MARX, Karl. Para a crítica da economia política. São Paulo: Abril Cultural, 1982.

(Série Os Economistas).

MARX, Karl. O capital: crítica da economia política. Livro1, volume I. Rio de Janeiro: Bertrand, 1989.

MONARCHA, Carlos. Escola Normal da Praça: o lado noturno das luzes. Campinas, SP: Editora da Unicamp, 1999. (Coleção Momento).

MORTATTI, Maria do Rosário Longo. Os s

entidos da alfabetização: São Paulo 1876-1994. São Paulo: Editora UNESP: CONPED, 2000. (Encyclopaidéia).

Museu da Estação da Luz. Corpus Internacional da Língua Portuguesa. João de Barros. $<$ http://200.150.149.165:9081/wps/portal/DocumentosBrasileiros >.

PERES, Eliane. Autoras de obras didáticas e livros para o ensino da leitura produzidos no Rio Grande do Sul: contribuições históricas da alfabetização (19501970). Educação Unisinos, 12 (2):111-121, maio/agosto 2008.

PRIMITIVO, Moacyr. A Instrução e o Império: Subsídios para a História da Educação no Brasil (1823-1853). $1^{\circ}$ Volume, Companhia Editora Nacional, São Paulo, 1936.

RATKE, Wolfgang. Escritos sobre A nova Arte de Ensinar de Wolfgan Ratke (15711635): textos escolhidos. Apresentação, tradução e notas de Sandino Holf. Campinas, SP: Autores Associados, 2008. (Coleção Clássicos da Educação).

REIS FILHO, C. A Educação e a Ilusão Liberal: origem da escola pública paulista. Campinas, S P: Autores Associados, 1995.

RIBEIRO, Maria Luisa Santos. História da educação brasileira: a organização escolar. São Paulo: Autores Associados, 1998

SAVIANI, Dermeval. Histórias das Idéias Pedagógicas no Brasil. Campinas, SP: Autores Associados, 2007. (Coleção Memória da Educação).

SCHELBAUER. Analete Regina. A Constituição do Método de Ensino Intuitivo na província de São Paulo (1870-1889). Tese (Doutorado em educação), Universidade de São Paulo, Faculdade de Educação. História da Educação e Historiografia. DEDALLUS Acervo - FE - 205000093698. 2003.

SILVA, Ceris Salte Ribas. As repercussões dos novos livros didáticos em alfabetização na prática docente. Belo Horizonte, 2003, Tese (Doutorado em Educação), Universidade Federal de Minas Gerais - Faculdade de Educação.

SILVA, Vivian Batista. Uma história de leitura para professores: um estudo da produção e circulação de saberes especializados nos "manuais pedagógicos" brasileiros (1930-1971), Dissertação de Mestrado, Universidade de São Paulo, Faculdade de Educação. DEDALUS - FE - 20500023414, São Paulo, 2001. 
SILVA, Vivian Batista. Saberes em viagem nos manuais pedagógicos: construções da escola em Portugal e no Brasil (1870-1970). ANPED, 29ª Reunião Anual/2006, GT 02. Disponível em <http://www.anped.org.br>. Acesso em 10/junho/2009.

\title{
SOARES, Magda e MACIEL, Francisca. Alfabetização no Brasil; o estado do conhecimento. BRASILIA, Inep/MEC/REDUC, 1989.
}

TANURI, Leonor Maria. O ensino Normal no Estado de São Paulo (1890-1930). DEDALUS - FE - Universidade de São Paulo, Faculdade de Educação, 1979.

\author{
VALDEMARIN, Vera Teresa. Estudando as lições de coisas: análise dos fundamentos \\ filosóficos do Método do Ensino Intuitivo. Campinas, SP: Autores Associados, 2004. \\ (Coleção Educação Contemporânea).
}

\begin{abstract}
1 Aprovada pelo Conselho Nacional de desenvolvimento Científico (CNPq), sob a Coordenação da Professora Dra. Silvia Helena Andrade de Brito, Coordenadora do GT MS do HISTEBR e professora do Departamento de Ciências Humanas e Letras/Centro de Ciências Humanas e sociais da Universidade Federal de Mato Grosso do Sul (UFMS). Os membros do grupo estão vinculados ao HISTEDBR, da unidade regional de Mato Grosso do Sul. Fazem parte da pesquisa: Universidade Estadual de Mato Grosso do Sul (UEMS), Universidade Federal de Mato Grosso do Sul (UFMS), UNIDERP/Anhanguera.

${ }^{2}$ As reformas educacionais abrangeram o ensino superior e médio. Na gestão de Gustavo Capanema foram criadas seis. A primeira delas iniciou com a lei que organiza o ensino industrial e que recebeu o nome de Lei Orgânica do Ensino Industrial (Lei n 4073, de 30 de janeiro de 1942); o segundo ramo destacado na reforma Capanema foi o ensino secundário, por meio da Lei Orgânica do Ensino Secundário (Decreto-Lei n 4.244, de 9 de abril de 1942); o ensino comercial foi reformulado pelo (Decreto-Lei ${ }^{\circ}$ 6141, de 28 de fevereiro de 1943); e articuladas na gestão de Capanema, mas colocadas em vigor em 1946, no período pós-Estado Novo, encontram-se três reformas, Leis Orgânicas do Ensino Primário, Normal e Agrícola. Lei Orgânica do Ensino Primário (Decreto-Lei $n^{\circ}$ 8529, de 2 de janeiro de 1946). Versou sobre a organização do ensino normal o (Decreto-Lei $\mathrm{n}^{\circ}$ 8530, de 2 de janeiro de 1946), a últimas das Leis Orgânicas desse período foi a que tratou sobre o ensino agrícola (Decreto-Lei 9613, de 20 de agosto de 1946). BRITO (2006).

${ }^{3}$ Getúlio Dorneles Vargas foi Presidente da República por dois períodos: o primeiro teve duração de 15 anos ininterruptos de 1930 a 1945 . Nesse período seu governo se articula em três momentos de 1930 a 1934, como chefe do governo provisório, de 1934 a 1937, pois não fora eleito, mas empossado por uma junta provisória quando depôs o mandato da República Velha e estabeleceu no país um regime ditatorial. E o terceiro momento deste primeiro mandato vai de 1937 a 1945, quando instaurou o Estado Novo, implantado após um golpe de Estado. E num segundo período, eleito por voto direto, governou o Brasil por três anos de 1951 a 1954. <http://pt.wikipedia.org/wiki/GetC3\%BAlio_Vargas >, acesso em 12/04/2010.
\end{abstract}

4 "Ciência da História" foi um termo conferido por Marx e Engels (1986), em A Ideologia Alemã, mas foi extinto quando da revisão final desse manuscrito. Porém, a denominação apesar de ter sido abolida de $A$ Ideologia Alemã, em face de outras expressões, tem a adesão dos autores que entendem que todas as obras humanas são históricas. (Cf. MARX, K. \& ENGELS, F. A Ideologia Alemã: Feuerbach. 5. ed. São Paulo, HUCITEC. 1986).

\footnotetext{
${ }^{5}$ A expressão manual didático refere-se aos Livros de texto próprios criados por Comênio, no século XVII, na constituição da Escola Moderna como instrumento que permitiria a universalização do ensino. Nesses livros, era prescrito todo programa conforme o número de classes de modo que, durante o espaço e o tempo de condução dos jovens nos estudos, não tenham a necessidade de nenhum outro livro. (Cf. COMÊNIO, 1957:430).
} 


\begin{abstract}
${ }^{6}$ Cartinha era um termo usado em língua portuguesa desde o princípio da Idade Média para identificar os textos impressos, usados para ensinar a ler, escrever e contar. Quando ainda não existiam livros didáticos os professores elaboravam textos manuscritos ou utilizavam cartas, ofícios e documentos de cartórios para o ensino da leitura e da escrita, daí a origem da palavra cartilha. (COLLARES, 2008). Entre as primeiras "cartilhas" figuram as cartinhas de aprender a ler, de autoria de João de Barros (1539) e em 1540 foi publicado em Lisboa a Gramática de Língua Portuguesa e o Diálogo em Louvor da Nossa Linguagem. A Cartinha de João de Barros, provavelmente usada no Brasil Colônia, foi possivelmente, o primeiro livro didático ilustrado da história. Barros, João de 1496-1570. ARAÚJO, Gabriel Antunes de (Organizador) (2008)
\end{abstract}

${ }^{7}$ Historiador, filósofo, escritor e pedagogo, humanista quinhentista, nasceu, provavelmente em 1496, em Vila Verde, perto de Viseu. Publicou em 1539 uma cartilha conhecida como Cartinha de João de Barros e em 1540, publicou o diálogo de João de Barros com dois filhos seus sobre preceitos morais e gramática de Língua Portuguesa, obra acompanhada do diálogo em louvor da nossa Linguagem.

http://200.150.149.165:9081/wps/portal/DocumentosBrasileiros.

${ }^{8}$ Orbis Sensualium Pictus de Comênio (1658) pequena enciclopédia que apresenta o saber elementar, didaticamente organizado sobre a base de imagens e palavras. A obra compõe-se de figuras, nomenclaturas e descrições. MIRANDA, Carlos E. A. Acesso em 02/03/2010. <http://www.labeduimagem.pro.br/frames/seminarios/pdf/caream.pdf >.

${ }^{9}$ A cartilha de João de Barros era dividida em duas partes, a primeira dedicada à instrução da leitura e a segunda ao preparo das crianças na religião católica. A parte introdutória constituída por vinte e dois desenhos de objetos trazia o abecedário, assim distribuído: no alto a palavra, logo abaixo o desenho, cuja primeira letra representa a correspondente do alfabeto em português. Cf. ARAÚJO, Gabriel Antunes de. (Org.) Cartinha com os Preceitos e Mandamentos da santa Madre Igreja: 1539. São Paulo: Humanitas: Paulistana, 2008.

${ }^{10}$ A tradução, apresentação e notas da obra, os Escritos sobre a Nova Arte de Ensinar de Ensinar de Wolfgang Ratke (1571-1635): textos escolhidos foi realizada pelo professor Sandino Hoff. - Cf. HOFF, Sandino. Escritos sobre a Nova Arte de Ensinar de Ensinar de Wolfgang Ratke (1571-1635): textos escolhidos. Campinas, SP: autores Associados, 2008.

11 "A cooperação fundada na divisão do trabalho adquire a sua forma clássica na manufatura. Predomina como forma característica do processo de produção capitalista, durante o período manufatureiro propriamente dito, que, grosso modo, vai de meados do século XVI ao último terço do século XVIII”. (MARX, 1989:386).

O grifo é nosso.

${ }^{13}$ Cf. A produção da escola pública contemporânea (2001) e O trabalho didático na escola moderna: formas históricas (2005).

${ }^{14}$ Essa Lei determina, em seu artigo $1^{\circ}$, que as escolas elementares devem existir em todas as cidades, vilas e lugares mais populosos. A Lei recomenda a adoção dos métodos e forma de organização preconizada pelo ensino mútuo e estipula os conteúdos que devem ser ensinados. (Cf. PRIMITIVO, 1936:189-191)

${ }^{15}$ Hoje, ensino médio.

${ }^{16}$ Criada pela Lei $\mathrm{N}^{\circ} .34$, de 16 de março de 1846.

${ }^{17}$ Conforme Reis Filho (1995): "Inspirando-se em autores europeus que difundiram as crenças básicas do liberalismo e do cientificismo, a intelectualidade brasileira defendia um programa de inovações considerado indispensável à elevação do Brasil ao nível do século. Isto é, pelas novas idéias, políticos e publicistas 
pretendiam realizar a atualização histórica, considerada como a forma de realização nacional. Entretanto, a própria maneira de perceber e de analisar a realidade sócio-cultural brasileira refletia as últimas teorias importadas que passavam a exercer dupla função: para diagnosticar a realidade e para propor soluções. $\mathrm{O}$ modelo pensado assumia a forma de projeto que passava para os programas partidários e daí era transformado em leis de organização política, judiciária, eleitoral ou educacional. É um período em que as propostas de reforma, de quase todas as instituições brasileiras existentes, entravam em debate, agitando o pequeno mundo intelectual e político da época. Porém as reformas não partiam da realidade, mas do modelo importado." (.213-214).

${ }^{18}$ Coleção publicada pela imprensa nacional com digitalização de Cartas de Leis, Decretos, Alvarás, Cartas Regias e decisões imperiais desde 1808 a 1889, acessado em 14 de abril de 2009, disponível em http://www2.camara.gov.br/legislacao/publicacoes/doimperio

${ }^{19}$ Couto Ferraz assumiu o posto de Ministro do Império em 6 de setembro de 1853, que lhe facultou baixar o regulamento que ficou conhecido como "Reforma Couto Ferraz" (SAVIANI, 2005:130).

${ }^{20}$ C.f BRASIL, Coleção das Leis do Império, Decreto 1331-A. (On Line).

${ }^{21}$ Abordando vários ramos e níveis do ensino, essa obra pode ser considerada o primeiro estudo de conjunto sobre a educação brasileira. (SAVIANI, 2005:135).

${ }^{22}$ O positivismo, a filosofia pleiteada por Augusto Comte (1996, p. 71) no século XIX "se compõe essencialmente de uma filosofia e de uma política, necessariamente inseparáveis, uma constituindo a base, a outra a meta de um mesmo sistema universal, onde inteligência e sociabilidade se encontram intimamente combinados. De uma parte, a ciência social não é somente a mais importante de todas, mas fornece, sobretudo, o único elo, ao mesmo tempo lógico e científico, que de agora em diante comporta o conjunto de novas contemplações reais". Augusto Comte pretendia através da sua "ciência positiva" realizar uma reforma geral na sociedade (em particular da francesa), que segundo ele se encontrava em estado de completa "perturbação política e econômica".

${ }^{23}$ Decreto de 12 de março de 1890. (On Line) Rev. Bras. Est. Pedagógico Brasília, v. 76, n 184, set/dez, 1995.

${ }^{24}$ Cf. Artigo $4^{\circ}$ e $9^{\circ}$ Parágrafo $1^{\circ}$ do Decreto-Lei n 7247.

${ }^{25}$ Ferdinand Buisson (1841-1927), foi inspetor e diretor do ensino primário francês, ocupou a cadeira de pedagogia na Sorbonne e colaborou em reformas escolares. Foi deputado e atuou em diversas ligas e sociedades em favor da instrução pública. Recebeu o prêmio Nobel da Paz em 1927. Suas idéias foram amplamente difundidas entre os intelectuais brasileiros no campo educacional. BASTOS, Maria Helena Câmara. Ferdinand Buisson no Brasil: Pistas, vestígios e sinais de suas idéias pedagógicas (1870-1900). Revista História da Educação, ASPHE/FAE/UFPeI, Pelotas, nº 8, p. 79-109, set. 2000. Apud Schelbauer, Tese (2003).

${ }^{26}$ Dietzsch (1979), Magnani (1997), Carvalho (1998), Amâncio (2000), Maciel (2001) e Trindade (2001).

${ }^{27}$ Congressos Luso-Brasileiros de história da Educação e Congressos da Sociedade Brasileira de História da educação.

${ }^{28}$ Estudar a cartilha paranaense com autores brasileiros teve inicio com o grupo de pesquisa História Sociedade e Educação no Brasil - HISTEDBR. O estudo é realizado no âmbito da linha de pesquisa "história das instituições escolares," constituída no grupo de estudos e Pesquisa "História Sociedade e Educação no Brasil nos campos Gerais - PR - HISTEDBR. 
${ }^{29}$ Cabe aqui registrar algumas pesquisas elencadas, no estudo de Collares sobre o uso das cartilhas como objeto de estudo, às quais ainda não se teve acesso: Helena Costa Lopes de Freitas (1979), Alfabetização e universo cultural: análises de cartilhas utilizadas nas escolas da cidade de Campinas. (UNICAMP). José Carlos Abraão (1990), Alfabetizar, quem se habilita?- analisa as cartilhas de modo geral e aquelas utilizadas na zona rural. (USP). Lázara Nanci de Barros Amâncio (1994), O espaço da cartilha na sala de aula. (UFG). Iole Maria Faviero Trindade (2001), A invenção de uma nova ordem para as cartilhas: ser Maternal, Nacional e Mestra: Queres Ler? (UDRG).

${ }^{30}$ Escritor, foi professor, atuou junto aos responsáveis pelo ensino público e destacou-se como Diretor em escola pública.

${ }^{31}$ Professora, Mestre e Doutora em história da educação pela Faculdade de Educação da USP.

${ }^{32}$ Trabalho apresentado na ANPED, 29a Reunião Anual/2006, Grupo de Trabalho (GT) 02. Disponível em $<\mathrm{http}: / /$ www.anped.org.br $>$.

33 Trabalho apresentado na ANPED, 30ª Reunião Anual/2007, GT 02. Disponível em <http:// www.anped.org.br>.

${ }^{34}$ O CEALE foi criado em 1990, como órgão complementar da Faculdade de Educação - UFMG -, com o objetivo de integrar grupos interinstitucionais de pesquisa, ação educativa e documentação na área de alfabetização e ensino português. Desde 1997, CEALE, da Faculdade de Educação, avalia os livros didáticos de alfabetização. A partir de 2002, esse Centro passou a avaliar também os dicionários e livros de língua portuguesa para o ensino fundamental.

www.ceale.fae.ufmg.br/acaoeducacional.php?catId=74\&txtId=85.

Traduzido para a Língua Portuguesa por Rui Barbosa, para ser adotado nas escolas públicas brasileiras.

Artigo recebido em: 20/03/2010

Aprovado para publicação em: 16/06/2010 